\title{
AN AUDIT ON KNOWLEDGE OF INTERN HOUSE OFFICERS ON CARDIO PULMONARY RESUSCITATION
}

\author{
S M D Chandraguptha \\ Consultant Anaesthetist Sri Lanka Navy \\ "Corresponding Author: Chandraguptha@ hotmail.com
}

Key words: resuscitation, life support

\begin{abstract}
Cardiopulmonary resuscitation should be known by all health workers. Advanced life support should be protocol driven and all first responders should be well trained in carrying this out. My aim in doing this audit was to assess the training and knowledge in a defined population of health workers. A three part questionnaire was designed by me and used for the purpose. The results revealed that most of the training has taken place while being a medical student, a better knowledge of cardio pulmonary resuscitation was shown by doctors who have had repeated training, the interns in the medical wards had a better knowledge than surgical interns, the interns were not following the protocol all the time and even though there was a regular weekly programme in the National hospital of Sri Lanka they were not attending the training programme
\end{abstract}

Cardio pulmonary resuscitation is a very important aspect of resuscitation which should be known by all. While basic life support is practiced by the lay person all first responders should be well versed in advanced life support. In Sri Lanka we follow the resuscitation council of United Kingdom guidelines and protocols when teaching and training medical students and doctors in resuscitation. In the Colombo medical faculty it is essential that medical students undergo training in BLS (basic life support) and ALS (Advanced life support) prior to their sitting the final examination. The College of Anaesthesiologists of Sri Lanka conducts a training programme every Tuesday at the accident and emergency department of the National hospital of Sri Lanka.

The first responders in the wards are the intern house officers. They have no time to call for help from senior house officers when a patient collapses. It is therefore essential that all intern house officers have a good knowledge and practice of BLS and
ALS if unnecessary deaths are to be avoided.

\section{Materials and Methods}

The objective of this audit was to assess the knowledge of intern medical officers on standard resuscitation practice guidelines on adult basic and advanced life support. The audit population was intern medical officers at the National hospital of Sri Lanka, castle street maternity hospital, and De Soysa maternity hospital. A total number of eighty six intern medical officers were selected randomly to take part in the audit. A questionnaire designed by me was distributed among them. Only seventy seven returned completed forms. The questionnaire consisted of three parts. It contained twenty three questions in all with two to four responses. Each participant was to answer all questions and hand them over. The questions were based on basic and advanced knowledge on cardio pulmonary resuscitation with respect to resuscitation council UK 2005 guidelines. 
Data were entered by the EPI info software and analysed using the statistical package for social sciences (SPSS,inc,Chicago) computer programme version 17.0. Mean, standard deviation (SD), minimum value, maximum value was obtained for the selected variables of study. Comparison between present status and the number of times participated in resuscitation training with mean score of knowledge compared using one way ANOVA(post-Hoc test) and for age and duration of work using the independent samples $\mathrm{T}$ - test. Data were reported as number and percentages and mean ${ }^{+}-$standard deviation, $\mathrm{P}$ value $<0.05$ taken as significant.

\section{Results}

The study population was age between 2629 years. Out of seventy seven house officers who returned the answered questionnaire seventy two had worked less than six months. Out of the seventy seven responders twenty nine were in the medical wards, twenty six were doing the surgical wards and twenty two were attached to the gynaecology and obstetrics wards. Twenty seven out of seventy seven responders had never participated in the weekly resuscitation training programme at the National Hospital Sri Lanka.

Table 1 Demographic data

\begin{tabular}{|l|l|l|}
\hline $\begin{array}{l}\text { Characteristics Age in } \\
\text { years }\end{array}$ & Frequency & $\%$ \\
\hline $26-27$ & 48 & 62.3 \\
\hline $28-29$ & 29 & 37.7 \\
\hline
\end{tabular}

\begin{tabular}{|l|l|l|}
\hline Duration of work & Frequency & $\%$ \\
\hline$\geq 6$ months & 72 & 93.5 \\
\hline$>6$ months & 5 & 6.5 \\
\hline
\end{tabular}

\begin{tabular}{|l|l|l|}
\hline Present status & Frequency & $\%$ \\
\hline Medicine & 29 & 37.7 \\
\hline Surgery & 26 & 33.8 \\
\hline
\end{tabular}

\begin{tabular}{|c|c|c|}
\hline Obs. \& Gynae & 22 & 28.6 \\
\hline $\begin{array}{l}\text { No. of training } \\
\text { programmes }\end{array}$ & Frequency & $\%$ \\
\hline None & 27 & 35.1 \\
\hline Once & 33 & 42.9 \\
\hline Two or more & 17 & 22.1 \\
\hline
\end{tabular}

Figure 1. Bar chart showing number of training sessions participated by medical students/house officers

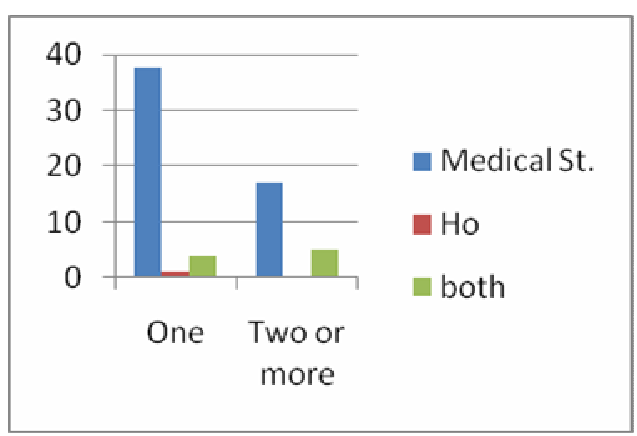

The above bar chart shows the number of times these house officers have undergone resuscitation training and their designations at the time. This clearly shows that most of these house officers had their resuscitation training as medical students.

The second part of the questionnaire consisted of eight questions to evaluate the knowledge on adult basic life support. (BLS)

\section{Table 2 Breakdown scores by questions -} BLS

\begin{tabular}{|l|c|c|}
\multicolumn{3}{|c|}{ Correct answer } \\
\hline $\begin{array}{l}\text { Question } \\
\begin{array}{l}\text { First criteria for } \\
\text { diagnosis of cardiac } \\
\text { arrest }\end{array}\end{array}$ & Freq & $\%$ \\
\hline Shout for help & 53 & 29.9 \\
\hline $\begin{array}{l}\text { Breathing normal - } \\
\text { assess airway }\end{array}$ & 45 & 68.8 \\
\hline Initial step in CPR & 39 & 58.4 \\
\hline $\begin{array}{l}\text { Rate of chest } \\
\text { compression }\end{array}$ & 58 & 50.6 \\
\hline $\begin{array}{l}\text { Depth of sternal } \\
\text { compression }\end{array}$ & 38 & 75.3 \\
\hline $\begin{array}{l}\text { Ratio of chest } \\
\text { compr. to rescue } \\
\text { breaths }\end{array}$ & 61 & 49.4 \\
\hline
\end{tabular}


\begin{tabular}{|l|c|c|}
\hline Duration of br. & 34 & 44.2 \\
\hline
\end{tabular}

The scores ranged from $29.9 \%$ to $79.2 \%$. $66.2 \%$ of participants had scores in the range of 4 to 8 . Fifteen participants had scores between 7 and 8 .

Table 3 Mean knowledge on adult advanced life support guidelines comparison with Demographic data.

\begin{tabular}{|l|c|c|c|c|l|}
\hline \multicolumn{1}{|c|}{ characteristics } & & Knowledge & & & \\
\hline Age & $\mathrm{n}$ & Range & Mean & SD & $\mathrm{pvalue}$ \\
\hline $26-27$ & 48 & $27.8-94.4$ & 53.1 & 16.2 & $\mathrm{t}=1.34$ \\
$28-29$ & 29 & $27.8-83.3$ & 48.3 & 14.1 & $\mathrm{p}=0.19$ \\
\hline Duration of work & & & & & \\
\hline $\begin{array}{l}\geq 6 \text { months - } \\
>\text { 6months }\end{array}$ & 72 & $27.8-94.4$ & 51.0 & 15.5 & $\mathrm{t}=0.63$ \\
\hline Present status & 5 & $33.3-72.2$ & 55.6 & 16.2 & $\mathrm{p}=0.53$ \\
\hline Medicine & 29 & $27.8-94.4$ & 58.4 & 14.7 & $\mathrm{f}=6.92$ \\
Surgery & 26 & $27.8-94.4$ & 50.0 & 16.4 & $\mathrm{p}=0.002$ \\
Obs \& Gynae & 22 & $27.8-72.2$ & 43.4 & 11.1 & \\
\hline $\begin{array}{l}\text { No. of training } \\
\text { sessions }\end{array}$ & & & & & \\
\hline None & 27 & $27.8-66.8$ & 44.4 & 10.9 & $\mathrm{f}=12.89$ \\
Once & 33 & $27.8-77.8$ & 49.7 & 13.5 & $\mathrm{p}<0.001$ \\
Two or more & 17 & $33.3-94.4$ & 65.4 & 17.0 & \\
\hline Total & 77 & $27.8-94.4$ & 51.3 & 15.5 & \\
\hline
\end{tabular}

The mean score of house officers who have never participated in resuscitation training programmes was $49.1 \pm 17.0 \%$ (range 12.5 $75.0 \%$ ) mean score of house officers who participated in two or more resuscitation programmes was $81.6 \pm 22.6 \%$ (range 25.0 - 100\%). This represented a highly significant difference in knowledge $(\mathrm{p}<0.001)$.

There is no significant difference in knowledge on BLS with age. There is a significant difference when it comes to duration of work as house officers. House officers with less than six months duration of work has a better knowledge of BLS.

There is a significant difference in knowledge depending on the present intern appointment. House officers who are in medicine have a better knowledge when compared to house officers in gynaecology and obstetrics. House officers who have undergone two or more training programmes have a better knowledge than house officers who have never participated in any training programme.

The $3^{\text {rd }}$ part of the questioner consisted of 18 questions on ALS.

Table 4. Breakdown scores by questions in relation to $\mathrm{ALS}$ guideline

\begin{tabular}{|l|c|c|}
\multicolumn{2}{|c|}{ Correct Answer } \\
\hline Question & frequency & $\%$ \\
\hline $\begin{array}{l}\text { Rhythm abnormalities in c. } \\
\text { arrest }\end{array}$ & 63 & 81.8 \\
\hline Defibrillation not appropriate & 34 & 44.2 \\
\hline The type of defibrillator & 52 & 67.5 \\
\hline Energy for monophasic de fib. & 16 & 20.8 \\
\hline $\begin{array}{l}\text { Adrenalin as immediate } \\
\text { treatment }\end{array}$ & 60 & 77.9 \\
\hline 1mg of adrenaline & 46 & 59.7 \\
\hline Atropine should not be given & 42 & 54.5 \\
\hline No. of shocks & 50 & 64.9 \\
\hline Management after DC shock & 52 & 67.5 \\
\hline Management of pulseless VT & 24 & 31.2 \\
\hline Half life of adrenaline & 37 & 48.1 \\
\hline Management after 3 shocks & 27 & 35.1 \\
\hline Irreversible causes & 46 & 59.7 \\
\hline Decision to stop resus. & 45 & 58.4 \\
\hline $\begin{array}{l}\text { Resuscitation of pregnant } \\
\text { patient }\end{array}$ & 19 & 24.7 \\
\hline Resuscitation of victim of drowning & 22 & 28.6 \\
\hline Tracheal intubation & 33 & 42.9 \\
\hline Incorrect reasons for intubation & 43 & 55.8 \\
\hline
\end{tabular}

There was no difference in knowledge in ALS with regard to age or duration of work as house officers. There is a significant difference in knowledge on ALS between the house officers in medicine when compared to house officers doing gynaecology and obstetrics. House officers in medicine had better knowledge. House officers who had two or more training sessions had better knowledge than house officers who had not undergone training. 
Table 5 Mean knowledge on adult BLS A comparison with demographic data

\begin{tabular}{|l|c|c|c|c|l|}
\hline characteristics & & Knowledge & & & \\
\hline Age & $\mathrm{n}$ & Range & Mean & SD & pvalue \\
\hline $26-27$ & 48 & $12.5-100$ & 60.4 & 24.8 & $\mathrm{t}=1.63$ \\
$28-29$ & 29 & $12.5-100$ & 51.3 & 22.0 & $\mathrm{p}=0.11$ \\
\hline Duration of work & & & & & \\
\hline $\begin{array}{l}\geq 6 \text { months - } \\
>\text { 6months }\end{array}$ & 5 & $12.5-100$ & 58.9 & 23.6 & $\mathrm{t}=2.70$ \\
& & & & & \\
\hline Present status & & & 30.0 & 11.2 & $\mathrm{p}=0.009$ \\
\hline Medicine & 29 & $25.0-100$ & 70.3 & 21.5 & $\mathrm{f}=8.79$ \\
Surgery & 26 & $12.5-100$ & 51.0 & 23.7 & $\mathrm{p}<0.001$ \\
Obs \& Gynae & 22 & $12.5-100$ & 46.6 & 20.1 & \\
\hline $\begin{array}{l}\text { No. of training } \\
\text { sessions }\end{array}$ & & & & & \\
\hline None & 27 & $12.5-75.0$ & 49.1 & 70.0 & $\mathrm{f}=16.05$ \\
Once & 33 & $12.5-100$ & 50.8 & 21.6 & $\mathrm{p}<0.001$ \\
Two or more & 17 & $25-100$ & 81.6 & 22.6 & \\
\hline Total & 77 & $12.5-100$ & 57.0 & 24.0 & \\
\hline
\end{tabular}

\section{Discussion}

Health care institutions have an obligation to provide an effective resuscitation service. To this end staff should receive regular training for maintaining a level of competence appropriate to their individual roles in hospital. National Hospital of Sri Lanka conducts a weekly training on cardio pulmonary resuscitation at the accident service to which any medical staff member can participate. In Sri Lanka this teaching at present is based on resuscitation council UK 2005 guidelines. These guidelines are scheduled to be updated at the end of 2010. It is timely to assess the knowledge of our medical staff on BLS and ALS.

Unfortunately cardiac arrests are poorly managed in our country. Lack of identification of the patients in impending cardiac arrests, poor management, lack of facilities and resources are among the main reasons. Prevention of cardiac arrests in critically ill patients is due to limited availability of High Dependency Units and intensive care facilities. Lack of knowledge inevitably results in poor management of cardiac arrests victims. This can be prevented by regular teaching and training. The results of our study show a significant number of house officers had never undergone any training in BLS and ALS. Our findings show that there is better knowledge in House Officers who have participated in cardio pulmonary resuscitation training programmes two or more times.

When we analysed the answers to questions individually what is lacking is detailed knowledge and on protocol led management. The management of pregnant cardiac arrest victims was very poorly answered. Cardiac arrest following drowning was also poorly answered.

There is definite room for improvement in the teaching and training on adult cardio pulmonary resuscitation in the following areas.

Shockable rhythms, management of pregnant cardiac arrests, cardiac arrest following drowning, intubation of cardiac arrest victims and the use of defibrillators.

It should be recommended that training in resuscitation should be made mandatory at least once during the early stages of internship.

\section{References}

1. Adult basic and advanced life support Resuscitation council UK guidelines 2005 on

2. Adult advanced life support European resuscitation council guidelines 2000

3. Cardio pulmonary resuscitation: standards for clinical practice and training: A joint statement from RCOA, Royal College of physicians London. Intensive care society and Resuscitation Council UK 2008 